Article

\title{
Web-Based Parenting Support: Development of the COPING Confident Parenting Programme
}

\author{
Judith Hutchings *, Dawn Owen and Margiad Williams \\ School of Psychology, Bangor University, Bangor LL57 2DG, UK; psp428@bangor.ac.uk (D.O.); \\ williams@bangor.ac.uk (M.W.) \\ * Correspondence: j.hutchings@bangor.ac.uk
}

Received: 7 March 2018; Accepted: 20 April 2018; Published: 23 April 2018

\begin{abstract}
Parents have the most significant impact on children's development and the key parenting factors that promote child development and wellbeing are well known. Furthermore, many behavioural, social and emotional problems in children are associated with poor parenting practices. Parenting interventions that address parental skill deficits and teach positive parenting principles based on social learning theory are effective and are the recommended treatment for conduct disorder. Alongside the development of treatment programmes, universal parenting programmes have been developed; many present the same core parenting principles but their rationales vary from promoting children's development to addressing common behavioural challenges and the evidence for these programmes is less well established. Most parents now have internet access and are making daily use of it, including seeking advice on parenting matters but that advice is often anecdotal and lacking evidence. In the meantime, a small number of web-based programmes, including parenting programmes have been developed and evaluated. This paper summarises the rationale for web-based universal programmes to support parents and briefly describes the history, content and a summary of the initial research on the COPING (confident parent internet guide) programme developed by the authors. The paper concludes with suggestions for future research directions.
\end{abstract}

Keywords: parenting; families; universal; web; evaluation

\section{Introduction}

Young children spend a lot of time with their parents and, even when they spend time in day-care, time spent with parents still has the single most significant influence on their development [1]. Good parenting makes an important contribution to preventing child mental health problems, promoting child health and well-being and achieving good child outcomes [2,3]. For example, at age nine, children's academic success is related to the number of words their parents were speaking to them at age three, with children exposed to restricted parental language during their preschool years having poor outcomes [4]. Good parenting includes a focus on encouraging positive behaviour, praising desirable behaviour, limit setting and teaching emotional regulation and problem-solving skills [5].

There are many risk factors for poor child outcomes particularly for disruptive behaviour difficulties, including poverty, young parenthood, single parenthood, maternal depression, unemployment and poor parental educational attainment [6]. However, it is the extent to which these risk factors compromise parenting that matters [7] rather than by direct influence on child behaviour and many randomised controlled trials (RCTs) have demonstrated the benefits of teaching positive parenting strategies to parents of children with behavioural difficulties $[5,8]$ including with those families experiencing significant social disadvantage $[9,10]$. 
Many parents report challenges in raising children [11]. The past half-century has seen dramatic lifestyle changes, some of which have brought benefits, such as advances in medical treatment, better working conditions and improved communication, however others present challenges with increasing consumption of ready meals, increased obesity in both children and adults, lack of exercise, overexposure to screens and sleep deprivation. These changes include children spending much time indoors, playing on computers or watching television, often in their own rooms away from the company of adults, and spending little time playing outside [12].

Exposure to the key parenting skills that are included in targeted interventions may be of universal benefit for parents in general, providing them with evidence-based information that teaches the knowledge, skills and competencies that encourage positive child development, well-being and good academic outcomes [13,14]. Sanders and colleagues [15] defined the rationale for a universal population-level approach as promoting children's social, emotional, language, intellectual and behavioural competencies through positive parenting practices.

It is clear however that most well-evaluated programmes target parents of children with disrupted behaviour, reaching only small numbers of families and are not universally available $[13,16-18]$. Consequently, families that are not experiencing clinical difficulties with their children but who are seeking advice and information have little access to evidence-based information on parenting.

There are a number of potential advantages to offering universal parenting programmes. These include: (1) providing support for parents whose children do not have problems but who are concerned to parent their children in ways that provide them with the best outcomes; (2) facilitating access to evidence-based information for parents who are facing common everyday parenting challenges, but not currently in receipt of services; (3) impacting on societal norms by promoting positive parenting principles; and (4) supporting parents in encouraging positive child development.

Many universal parenting programmes are based on the same theoretical underpinnings as targeted/preventive programmes and teach the same positive parenting behaviours as programmes that address behavioural challenges. Some have shown promise $[19,20]$ however often they have recruited samples reporting significant levels of child behaviour problems and have mostly been evaluated in terms of level of reduction in challenging child behaviour [2,20-22].

Some universal programmes include components that focus on enhancing child development (promoting linguistic and/or cognitive skills), others target reductions in common everyday behavioural problems and both have demonstrated promising positive outcomes $[2,20,23]$. However, universal parenting programmes in general have not yet been extensively researched [2] and there is relatively little evidence of their effectiveness. The UK government funded Early Intervention Foundation, that evaluates and publishes standards of evidence for programmes, says that there is, to date, only preliminary evidence of improved outcome from universal programmes and an assumption of causal impact cannot be drawn [24].

Health visitors in the UK are tasked with supporting all families of pre-school children, however growing demands on health visitors' time to support parents with children with challenging behaviour reduces their ability to support all parents at a time when parents are bringing up children in a rapidly changing world with additional challenges [12]. This leaves many parents without access to potentially good quality face to face advice when dealing with everyday parenting challenges so parents are turning to other sources of information.

Internet access is now widespread as a result of cheaper internet providers and its availability on mobile phones and tablets and growing numbers of people now access it on a daily basis [25]. The internet offers flexible access within the home [26,27]. The advantages of web-based programmes to target public health concerns include convenience, relatively low cost of dissemination, the ability to reach more individuals and a destigmatising method for people to access information $[26,28]$. It also provides the opportunity to incorporate behavioural principles (e.g., audio, video and feedback) to target both engagement and behaviour change [26,28]. Already, web-based interventions have been shown to be effective in promoting health related behaviours including smoking 
cessation, hand washing, advice on eczema treatment, managing cancer related fatigue and weight reduction [29-33].

The internet is a fast-growing resource for modern-day parents and the majority of parents $(75 \%)$ now use social media to obtain parent-related information [34]. In 2008, a yahoo search using the keyword 'parenting' found around 270,000,000 websites [35] and over eight million people visit one online parenting information and advice website every month [36]. The web provides an opportunity to introduce social learning theory-based parenting principles using the same principles in both content and programme delivery $[37,38]$. These include shaping and reinforcing behaviour, modelling skills and encouraging rehearsal of skills as well as prompting positive behaviour through practical assignments to be undertaken with children [38].

\section{Evidence for Internet-Based Programmes}

There is evidence of benefits following web-based parenting interventions [39]. However, high attrition rates have been reported $[21,40]$ with many participants, particularly those reporting significant child behavioural challenges [41], starting but not completing programmes [27] and there is limited RCT evidence.

A recent systematic review of web-based parenting programmes [41] included programmes targeting the age range 0-18 years. Programmes had to be digital and to have been peer reviewed and not targeting a specific problem such as autism. Only 11 studies, published since 2000, met these criteria, reporting on seven interventions and nine delivery methods. Half or less of the studies had data for most of the comparisons. Only one study had an ethnically diverse population, four studies had middle income participants and two had low income parents with only $15 \%$ having less than high school education. Nine programmes described the method (six internet, two cd-rom, one a reality tv show) and eight provided content descriptions, all used video modelling, other content was delivered via text, narrated text, check in questions, and interactive activities. Six studies reported some additional human contact. The programmes ranged from 1-12 sessions in length and completion rates varied from 41-99.2\%. Overall longer programmes had lower completion. Five studies reported high satisfaction and one reported low satisfaction. Five programmes also had individualised support but the study did not test its effect so it was not clear to what extent additional support might be helpful or for whom. Only four studies reported parent and child outcomes with overall effect sizes for child outcomes in terms of reductions of behaviour problems of .61 and for parent outcomes 0.46 and there was evidence for video modelling being helpful.

Conclusions from the review were tentative because of the varied programme lengths and wide age range and nothing could be concluded about low income/vulnerable families, ethnic minorities or the benefits of additional support.

\section{The COPING Parent Online Universal Programme}

In Wales we have been developing and evaluating a universal web-based programme, the Confident Parent Internet Guide (COPING) programme. To date we have undertaken a pilot trial [42] and a small RCT [43,44]. This paper describes the programme and summarises reported outcomes. The COPING parent programme is intended for parents of children aged 3-8 years with the aim of encouraging positive parenting and promoting positive child development and well-being. It is based on 'The Little Parent Handbook' [45] that contains a summary of social learning theory based positive parenting principles developed over many years from trials of targeted and preventive interventions [9,46-48]. COPING presents these evidence-based behavioural principles $[37,49,50]$ associated with good child outcomes and also includes components that promote children's development by encouraging language skills and teaching parents skills of prompting, shaping, modelling and reinforcing desirable behaviour [9,51].

The intervention has eight content and two revision chapters [43]. The topics are:

i. $\quad$ Spending special time with your child through play 
ii. Encouraging good behaviour through praising

iii. Encouraging good behaviour through rewarding

iv. How to get better at giving instructions [part 1]

v. How to get better at giving instructions [part 2]

vi. Revision [a review of chapters 1-5]

vii. Ignoring problem behaviour

viii. Teaching your child new behaviours

ix. How to develop your child's language skills

x. Revision [a review of chapters 1-9]

The COPING programme incorporates core social learning theory principles [37] in its presentation, including modelling, prompting, and reinforcing desirable behaviour. The principles are introduced through video examples of positive parenting (modelling), parents are prompted to set and record achievable goals, achievement is monitored and reinforced by online feedback and multiple-choice quizzes which are reinforced with feedback for correct responses [43].

Parents are provided with a link to the website, a username and password and contact details of an administrator for any technical support needed. They are asked to log in and complete one chapter each week, each chapter takes approximately thirty minutes to complete. The software ensures that parents complete each chapter before they can move to the next one. Log in details allow parents to access the programme as many times as they wish. The intervention is programmed to take parents to the page that they last viewed on the next occasion that they log in. In order to give parents sufficient time to practice the principles outlined in the individual chapters, the intervention is programmed so that there is a minimum five-day gap between each chapter. If parents $\log$ in before the five days have elapsed, they are offered the opportunity to look back over previously completed chapters [43].

The programme enables the tracking of individual usage data including the number of log-ins, time spent on each page and the number of chapters completed. A text message is sent five days after the completion of each chapter informing the parent that the next chapter is now available. If the parent has not logged into the next chapter within three days of it becoming available, a reminder text is sent prompting them to log in and complete the next chapter. If a parent still has not logged in, weekly reminders are sent.

Parents read through information (or listen via an audio button if they prefer) and watch video examples of positive parenting. The video clips are short (all less than one minute long) allowing the opportunity for multiple viewing. At the end of each chapter there is a longer video and parents are asked to answer three questions based on it (by selecting yes or no) to encourage them to identify positive parenting behaviours. Each chapter ends with a multiple-choice quiz to test parents' knowledge and understanding of the key principles. Parents receive automated feedback on the correct answers, based on their quiz scores. They also have an option to download and print a summary sheet for each chapter [43].

Each chapter contains a suggested practice activity. The programme encourages parents to spend time playing with their child in order to strengthen their relationship, and they are reminded to engage in this activity throughout the programme. Parents can record online each week how many times they have played with their child from a drop-down menu. A praise message congratulates the parent for spending time with their child if they report spending time with their child. If parents do not report spending time with their child during the past week, a prompt message reminds them of the importance of this activity.

Minor modifications, made based on the feedback from the pilot trial [42], included text message prompting to remind parents to log-in to subsequent sessions, more video examples of positive parenting and the option to look back over previously completed chapters again. The revised programme was tested in a pilot RCT [43,44]. Although widely advertised through nurseries and health centres, and recruitment emphasised that this was a universal programme the sample was 
mainly recruited by word of mouth, generally by health visitors and other professionals as opposed to the self-referred parents and consisted of predominantly affluent and well-educated parents $[9,51,52]$.

Over $60 \%$ of parents who enrolled reported their child as scoring above the clinical cut-off on one or both of the Eyberg Child Behavior Inventory (a parent report inventory of challenging child behaviours) intensity and problem sub-scales [53] and over $40 \%$ of parents scored above the clinical cut off on the General Health Questionnaire (a screening tool for mental health difficulties in adults) [54]. Results from the Arnold et al. [55] parenting scale that identifies three aspects of problematic parenting showed that, in comparison to the mean scores of parents of children without behavioural problems, the mean sample scores were problematic on all three sub-scales. The subscales cover laxness (failure to set limits), verbosity (repeating threats but not following through) and over-reactivity (anger).

The programme was evaluated mainly through observation of parent-child interactions using the well-established Dyadic Parent-child Interaction Coding Scheme (DPICS) [56]. Immediate postintervention data showed significant reductions in observed indirect (or poor quality) commands and significant increases in observed praise relative to control participants with medium-large effect sizes. There were also non-significant reductions in parent reported child problem behaviours that showed medium effect size differences. Significant intervention improvements were also found at six-months post intervention for observed indirect commands, observed praise and observed negative parenting and parent reported child and parent behaviour [44].

Programme engagement was variable and, like other web-based studies, completion rates were poor [41]. Parents who were recruited but did not engage at all with the programme were experiencing more mental health problems compared with parents who engaged and parents lost at follow-up were more likely to have a lower level of education and be younger parents [44]. Nevertheless, these preliminary results suggest the value of further developing and testing of the COPING programme and this has been supported by a small grant from the Welsh Government to enable the transfer of the programme to enable access via an App. One local Authority in Wales is now working with us to further pilot the programme and we are seeking further funds to take this work forward. In a separate study we have developed a web-based programme for school support staff that is similar but uses classroom-based videos and this too has demonstrated feasibility and some indication of positive outcomes [57].

\section{Discussion}

Teaching parents positive parenting skills promotes child health and well-being and prevents child mental health problems [2,3]. Universal parenting programmes are designed to provide parents with evidence-based knowledge and skills to promote children's social, emotional, and language skills $[13,14]$. However, there is a lack of research regarding their effectiveness [2]. The web provides a platform to teach positive parenting skills to more parents at a relatively low cost $[26,28]$ and there is some supporting evidence [39,41]. COPING is a web-based universal parent programme developed and evaluated in Wales. Initial evidence is promising with significant improvements in parenting and child behaviour [44].

At present many programmes, including our own, have tended to recruit significant numbers of parents reporting high levels of behavioural problems in their children [20-22]. Such parents, however, are more likely to fail to engage or complete the programme [41], suggesting that programmes may need different content and/or additional therapist support to be effective for these parents.

Although other factors such as stigma may prevent some parents from seeking help from professionals, the extent to which parents of high challenge children are enrolling on web-based programmes [2,20-22] also suggests that there are insufficient targeted services for these parents. Parents are turning to the web to get parenting advice which highlights the need for evidence based or informed programmes to address the recruitment of universal populations. Despite our efforts to recruit with flyers through nurseries this had only limited success and our own study recruited 
predominantly by word of mouth and referral by health visitors. Other recruitment strategies need to be explored in future studies.

Programme engagement is a common problem for universal parenting programmes [27,41] and our own research was no exception. Almost half the participants either only completed the first chapter or did not log in to the programme at all. This may be due to the lack of prompting of participants between sessions. Text message prompts were programmed into the COPING programme to be sent to parents, however this did not happen due to technical difficulties. Since parents had to wait five days between each chapter, and the text messages did not work, it is possible that the low engagement is due to parents forgetting to log in to the next chapter. Studies who have provided prompts to parents to remind them to complete sessions show better rates of engagement [21], therefore the addition of prompts in further trials may increase engagement rates.

Most of the trials of web-based programmes to date, including our own, have had small numbers of participants meaning that it is not possible to explore the relative effectiveness of the programme for parents of children with clinical levels of behaviour problems versus children with non-clinical levels. Programmes need to be clear regarding intended populations, goals and outcomes.

Other components of COPING require evaluation for example the requirement to wait five days before being able to log on to the next chapter. Whilst this was designed to allow time for parents to practice the chapter content before moving on, which is essential for learning new skills [38], for a universal audience this may not be essential. The ability to 'skip' content to get to information that is personally relevant to them may contribute to increased engagement since parents do not have to work through sessions that are irrelevant to their situation. The effect of the extent of control over parents' pacing through programmes is an under-researched area [41] and needs further evaluation.

\section{Conclusions}

Preliminary evidence, from both our own and other programmes, suggests that web-based parenting support is beneficial. However, the goals and outcome measures used in universal programmes vary with some evaluating reductions in common behaviour problems and other targeting the promotion of child developmental outcomes such as language expression and comprehension and cognitive stimulation.

Stand-alone universal parenting programmes, without therapist support, can address the growing need for many parents to access evidence-based parenting advice on minor frequently occurring problems and promote children's healthy development, wellbeing and linguistic and cognitive development [58]. However, programmes need to explore whether the needs of parents reporting high levels of challenging child behaviour can also be met with stand-alone programmes or whether more support is needed and/or whether content needs to be different for such parents. This requires studies that have larger samples to explore differential effectiveness.

There is strong evidence for the benefits of teaching developmentally appropriate core behavioural principles to parents [59]. More work needs to be done on recruitment and to establish the content and delivery style components that are effective for parents with differing needs. Trials need larger numbers to address these issues and to be able to explore for whom which programmes work best and when, and for whom, additional off-line support is needed to encourage programme completion. Much of the advice obtained online by parents currently lacks evidence. Web-based programmes can provide evidence-based parenting support to address the growing universal demand for parenting advice.

Author Contributions: Conceptualisation, J.H., D.O. and M.W.; Writing-original draft preparation, J.H.; Writing-review and editing, D.O. and M.W.

Conflicts of Interest: J.H. and D.O. are the developers of the COPING online parent programme. M.W. declares no conflict of interest. 


\section{References}

1. Belsky, J. Quantity of Nonmaternal Care and Boys' Problem Behavior/Adjustment at Ages 3 and 5: Exploring the Mediating Role of Parenting. Psychiatry 1999, 62, 1-20. [CrossRef] [PubMed]

2. Ulfsdotter, M.; Enebrink, P.; Lindberg, L. Effectiveness of a universal health-promoting parenting program: A randomized waitlist-controlled trial of All Children in Focus. BMC Public Health 2014, 14, 108. [CrossRef] [PubMed]

3. Gardner, F.; Shaw, D.S.; Dishion, T.J.; Burton, J.; Supplee, L. Randomized prevention trial for early conduct problems: Effects on proactive parenting and links to toddler disruptive behavior. J. Fam. Psychol. 2007, 21, 39. [CrossRef] [PubMed]

4. Hart, B.; Risley, T.R. Meaningful Differences in the Everyday Experience of Young American Children; Paul H Brookes Publishing: Baltimore, MD, USA, 1995.

5. Furlong, M.; McGilloway, S.; Bywater, T.; Hutchings, J.; Smith, S.M.; Donnelly, M. Cochrane Review: Behavioural and cognitive-behavioural group-based parenting programmes for early-onset conduct problems in children aged 3 to 12 years (Review). Cochrane Database Syst. Rev. 2012, 2, 1-362. [CrossRef] [PubMed]

6. Farrington, D.; Welsh, B.C. Saving Children from a Life of Crime: Early Risk Factors and Effective Interventions; Oxford University Press: New York, NY, USA, 2007.

7. Patterson, G.R.; Forgatch, M.S.; Yoerger, K.L.; Stoolmiller, M. Variables that initiate and maintain an early-onset trajectory for juvenile offending. Dev. Psychopathol. 1998, 10, 531-547. [CrossRef] [PubMed]

8. National Institute for Health and Care Excellence (NICE). Antisocial Behaviours and Conduct Disorder in Children and Young People: Recognition, Intervention and Management (No. 158); National Institute for Health and Care Excellence: London, UK, 2013.

9. Hutchings, J.; Bywater, T.; Daley, D.; Gardner, F.; Whitaker, C.; Jones, K.; Eames, C.; Edwards, R.T. Parenting intervention in Sure Start services for children at risk of developing conduct disorder: Pragmatic randomised controlled trial. BMJ 2007, 334, 678. [CrossRef] [PubMed]

10. Gardner, F.; Hutchings, J.; Bywater, T.; Whitaker, C. Who benefits and how does it work? Moderators and mediators of outcome in an effectiveness trial of a parenting intervention. J. Clin. Child Adolesc. 2010, 39, 568-580. [CrossRef] [PubMed]

11. ZERO TO THREE. Tuning I National Parent Survey; ZERO TO THREE: Washington, DC, USA, 2016.

12. Palmer, S. Toxic Childhood: How the Modern World Is Damaging Our Children and What We Can Do about It; Orion: London, UK, 2006.

13. Sanders, M.R. Triple P-positive parenting programme as a public health approach to strengthening parenting. J. Fam. Psychol. 2008, 22, 506-517. [CrossRef] [PubMed]

14. Lindsay, G.; Strand, S.; Cullen, M.; Cullen, S.; Band, S.; Davis, H.; Conlon, G.; Barlow, J.; Evans, R. Parenting Early Intervention Programme Evaluation; Department for Education: London, UK, 2011.

15. Sanders, M.R.; Cann, W.; Markie-Dadds, C. The Triple P-Positive Parenting Program: A universal population-level approach to the prevention of child abuse. Child Abuse Rev. 2003, 12, 155-171. [CrossRef]

16. Sanders, M.R.; Turner, K.M.; Markie-Dadds, C. The development and dissemination of the Triple P-Positive Parenting Program: A multilevel, evidence-based system of parenting and family support. Prev. Sci. 2002, 3, 173-189. [CrossRef] [PubMed]

17. Foster, E.M.; Prinz, R.J.; Sanders, M.R.; Shapiro, C.J. The costs of a public health infrastructure for delivering parenting and family support. Child Youth Serv. Rev. 2008, 30, 493-501. [CrossRef]

18. Lindsay, G.; Totsika, V. The effectiveness of universal parenting programmes: The CANparent trial. BMC Psychol. 2017, 5, 35. [CrossRef] [PubMed]

19. Reedtz, C.; Handegard, B.H.; Morch, W.T. Promoting positive parenting practices in primary pare: Outcomes and mechanisms of change in a randomized controlled risk reduction trial. Scand. J. Psychol. 2011, 52, 131-137. [CrossRef] [PubMed]

20. Zubrick, S.R.; Ward, K.A.; Silburn, S.R.; Lawrence, D.; Williams, A.A.; Blair, E.; Robertson, D.; Sanders, M.R. Prevention of child behaviour problems through universal implementation of a group behavioural family intervention. Prev. Sci. 2005, 6, 287. [CrossRef] [PubMed] 
21. Sanders, M.; Calam, R.; Durand, M.; Liversidge, T.; Carmont, S.A. Does self-directed and web-based support for parents enhance the effects of viewing a reality television series based on the Triple P-Positive Parenting Programme? J. Child Psychol. Psychol. 2008, 49, 924-932. [CrossRef] [PubMed]

22. Wilson, K.R.; Havighurst, S.S.; Harley, A.E. Tuning in to Kids: An effectiveness trial of a parenting program targeting emotion socialization of pre-schoolers. J. Fam. Psychol. 2012, 26, 56-65. [CrossRef] [PubMed]

23. Hutchings, J.; Griffith, N.; Bywater, T.; Williams, M.E. Evaluating the Incredible Years Toddler Parenting Programme with parents of toddlers in disadvantaged (Flying Start) areas of Wales. Child Care Health Dev. 2017, 43, 104-113. [CrossRef] [PubMed]

24. Early Intervention Foundation. 2017. Available online: http://www.eif.org.uk/eif-evidence-standards / (accessed on 12 October 2017).

25. Office for National Statistics. Statistical Bulletin. Internet Access-Internet Users in the UK; Office for National Statistics: London, UK, 2016.

26. Gold, B.C.; Burke, S.; Pintauro, S.; Buzzell, P.; Harvey-Berino, J. Weight loss on the web: A pilot study comparing a structured behavioural intervention to a commercial programme. Obesity 2006, 15, 155-164. [CrossRef] [PubMed]

27. Wantland, D.J.; Portillo, C.J.; Holzemer, W.L.; Slaughter, R.; McGhee, E.M. The effectiveness of a web-based versus non-web-based interventions: A meta-analysis of behavioural change outcomes. J. Med. Internet Res. 2004, 6, e40. [CrossRef] [PubMed]

28. Alexander, G.L.; McClure, J.B.; Calvi, J.H.; Divine, G.W.; Stopponi, M.A.; Rolnick, S.J.; Heimendinger, J.; Tolsma, D.D.; Resnicow, K.; Campbell, M.K.; et al. A randomised clinical trial evaluating online interventions to improve fruit and vegetable consumption. Am. J. Public Health 2010, 100, 319-326. [CrossRef] [PubMed]

29. Strecher, V.J.; McClure, J.; Alexander, G.; Chakraborty, B.; Nair, V.; Konkel, J.; Greene, S.; Couper, M.; Carlier, C.; Wiese, C.; et al. The role of engagement in a tailored web-based smoking cessation programme: Randomised controlled trial. J. Med. Internet Res. 2008, 10, e36. [CrossRef] [PubMed]

30. Hustad, J.; Barnett, N.; Borsari, B.; Jackson, K.M. Web-based alcohol prevention for incoming college students: A randomized controlled trial. Addict. Behav. 2010, 35, 183-189. [CrossRef] [PubMed]

31. Brown, J.; Michie, S.; Geraghty, A.W.; Yardley, L.; Gardner, B.; Shahab, L.; West, R. Internet-based intervention for smoking cessation (StopAdvisor) in people with low and high socioeconomic status: A randomised controlled trial. Lancet Respir. Med. 2014, 2, 997-1006. [CrossRef]

32. Little, P.; Stuart, B.; Hobbs, F.D.R.; Moore, M.; Barnett, J.; Popoola, D.; Middleton, K.; Kelly, J.; Mullee, M.; Raferty, J.; et al. An internet-delivered hand washing intervention to modify influenza-like illness and respiratory infection transmission (PRIMIT): A primary care randomised trial. Lancet 2015, 386, 1631-1639. [CrossRef]

33. Little, P.; Stuart, B.; Andreou, P.; McDermott, L.; Joseph, J.; Mullee, M.; Moore, M.; Broomfield, S.; Thoams, T.; Yardley, L. Primary care randomised controlled trial of a tailored interactive website for the self-management of respiratory infections (Internet Doctor). BMJ Open 2016, 6, e009769. [CrossRef] [PubMed]

34. Duggan, M.; Lenhart, A.; Lampe, C.; Ellison, N.B. Parents and Social Media; Pew Research Centre: Washington, DC, USA, 2015; pp. 1-37. Available online: http://www.pewinternet.org/2015/07/16/parents-and-socialmedia / (accessed on 14 November 2017).

35. Fetsch, R.J.; Hughes, R.; Collins, C.L. Evaluating Family Life Web Sites; Colorado State University Extension; Colorado State University: Fort Collins, CO, USA, 2000.

36. Netmums. Available online: https:// netmums.com/home/about-us (accessed on 13 November 2017).

37. Bandura, A.; Walters, R.H. Social Learning Theory; Prentice Hall: Englewood Cliffs, NJ, USA, 1977.

38. Hutchings, J.; Gardner, F.; Lane, E. Making evidence based interventions work in clinical settings: Common and specific therapy factors and implementation fidelity. In Support from the Start: Working with Young Children and Their Families to Reduce the Risks of Crime and Antisocial Behaviour; Sutton, C., Utting, D., Farrington, D., Eds.; Department for Education and Skills: London, UK, 2004; pp. 69-79, ISBN 1844782034.

39. Enebrink, P.; Högström, J.; Forster, M.; Ghaderi, A. Internet-based parent management training: A randomised controlled study. Behav. Res. Ther. 2012, 50, 240-249. [CrossRef] [PubMed]

40. Arden-Close, E.; Smith, E.; Bradubury, K.; Morrison, L.; Denninson, L.; Michaelides, D.; Yardley, L. A visualisation tool to analyse usage of web-based interventions: The example of positive online weight reduction (POWeR). JMIR Hum. Factors 2015, 2, e8. [CrossRef] [PubMed] 
41. Breitenstein, S.M.; Gross, D.; Christophersen, R. Digital Delivery Methods of Parenting Training Interventions: A Systematic Review. Worldv. Evid. Based. Nurs. 2014, 11, 168-176. [CrossRef] [PubMed]

42. Owen, D.A.; Hutchings, J. An evaluation of the online universal programme COPING Parent: A feasibility study. J. Public Health Res. 2017, 6, 37-43. [CrossRef] [PubMed]

43. Owen, D.A.; Griffith, N.; Hutchings, J. Evaluation of the COPING parent online universal programme: Study protocol for a pilot randomised controlled trial. BMJ Open 2017, 7, e013381. [CrossRef] [PubMed]

44. Owen, D.A.; Williams, M.E.; Hutchings, J. An evaluation of the COPING parent online universal programme: A pilot randomised controlled trial. Manuscript in preparation, 2018.

45. Hutchings, J. The Little Parent Handbook, 1st ed.; Children's Early Intervention Trust: Bangor, UK, 2013.

46. Hutchings, J.; Appleton, P.; Smith, M.; Lane, E.; Nash, S. Evaluation of two treatments for children with severe behaviour problems: Child behaviour and maternal mental health outcomes. Behav. Cogn. Psychother. 2002, 30, 279-295. [CrossRef]

47. Lane, E.; Hutchings, J. Benefits of a course in behavioural analysis for health visitors. Br. J. Nurs. 2002, 11, 702-714. [CrossRef] [PubMed]

48. Williams, M.E.; Hutchings, J. The effectiveness of an individually delivered parenting programme for parents of children with behaviour problems: A pragmatic, pilot randomised controlled trial. Manuscript in preparation, 2018.

49. Patterson, G.R. Coercive Family Process; Castalia Publishing Company: Eugene, OR, USA, 1982; Volume 3.

50. Cooper, J.O.; Heron, T.E.; Heward, W.L. Applied Behaviour Analysis, 2nd ed.; Merrill Prentice Hall: Upper Saddle River, NJ, USA, 2007; pp. 37-46.

51. Gardner, F.; Burton, J.; Klimes, I. Randomised controlled trial of a parenting intervention in the voluntary sector for reducing child conduct problems: Outcomes and mechanisms of change. J. Child Psychol. Psychiatry 2006, 47, 1123-1132. [CrossRef] [PubMed]

52. Scott, S.; Webster-Stratton, C.; Spender, Q.; Doolan, M.; Jacobs, B.; Aspland, H. Multicentre controlled trial of parenting groups for childhood antisocial behaviour in clinical practice. Commentary: Nipping conduct problems in the bud. BMJ 2001, 323, 194. [CrossRef] [PubMed]

53. Eyberg, S.; Boggs, S.R.; Reynolds, L.A. Eyberg Child Behaviour Inventory; University of Oregon Health Sciences Center: Portland, OR, USA, 1980.

54. Goldberg, D.P. Manual of the General Health Questionnaire; Nfer Nelson: Windsor, UK, 1978.

55. Arnold, D.S.; O'Leary, S.G.; Wolff, L.S.; Acker, M.M. The Parenting Scale: A measure of dysfunctional parenting in discipline situations. Psychol. Assess. 1993, 5, 137-144. [CrossRef]

56. Eyberg, S.; Robinson, E. Dyadic Parent-Child Interaction Coding System: A Manual; The Parenting Clinic, University of Washington: Washington, DC, USA, 1981.

57. Jones, A.; Williams, M.E.; Owen, D.A.; Hutchings, J. Evaluation of the SKILLS (Support for Kids In Learning and Language Strategies) online programme for school support staff. Manuscript in preparation, 2018.

58. Baumel, A.; Pawar, A.; Kane, J.M.; Correll, C.U. Digital Parent Training for Children with Disruptive Behaviors: Systematic Review and Meta-Analysis of Randomized Trials. J. Child Adolesc. Psychopharmacol. 2016, 26, 740-749. [CrossRef] [PubMed]

59. Ary, D.; Glang, A.; Irvine, B. The Benefits, Science and Persuasive Technology of Successful e-Health Behavioural Interventions: Effective Use of Evidence-Based Scientific Techniques to Change Health Behaviour; ORCAS: Eugene, OR, USA, 2012.

(C) 2018 by the authors. Licensee MDPI, Basel, Switzerland. This article is an open access article distributed under the terms and conditions of the Creative Commons Attribution (CC BY) license (http:/ / creativecommons.org/licenses/by/4.0/). 